\title{
B-Cell Translocation Gene 2 Is Over-Expressed in Peri-Infarct Neurons after Ischaemic Stroke
}

\author{
M. Slevin ${ }^{a, b} \quad$ C. Sanfeliu ${ }^{d}$ M.M. Turu ${ }^{b}$ M. Grau-Olivares ${ }^{e} \quad$ I. Ferrer ${ }^{f} \quad$ S. Boluda ${ }^{f}$ \\ $\begin{array}{lll}\text { J. Marti-Fabregas } & \text { S. Kumar } & \text { P. Kumar } \\ & \text { J. Krupinskig, h }\end{array}$

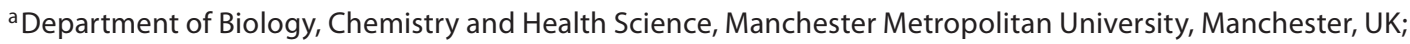 \\ ${ }^{b}$ Centro de Investigación Cardiovascular, CSIC-ICCC, and 'Servicio de Neurologia, Hospital de la Santa Creu i Sant Pau, \\ ${ }^{d}$ Department of Pharmacology and Toxicology, Institut d'Investigations Biomèdiques de Barcelona, CSIS, IDIBAPS, \\ e Department of Neurology, Stroke Unit, Hospital Universitari del Sagrat Cor, ${ }^{\mathrm{f}}$ Institut de Neuropatologia, \\ Servei Anatomia Patològica, IDIBELL, Hospital Universitari de Bellvitge, ${ }^{9}$ Department of Neurology, Stroke Unit, \\ Hospital Universitario de Bellvitge, and h Institut d'Investigació Biomedica de Bellvitge, Barcelona, Spain
}

\section{Key Words}

B-cell translocation gene $2 \cdot$ Neuronal survival $\cdot$ Ischaemic stroke

\begin{abstract}
Objectives: Recovery from stroke is dependent on the survival of neurons in the dynamic peri-infarcted region. Although several markers of neuronal injury and apoptotic cell death have been described, administration of neuroprotective drugs directed at specific molecules has had limited success. A complete understanding of deregulated genes associated with neuronal death would be beneficial. Our previous microarray studies identified increased expression of a novel protein, the B-cell translocation gene 2 (BTG2), in infarcted regions. Methods: We have used immunohistochemistry and Western blotting to examine the expression and localization of BTG2 in stroked brain tissue and immunofluorescent staining of human fetal brain neurons to determine if oxygen-glucose deprivation affected its expression. $\boldsymbol{R e}$ sults: We show that BTG2 is strongly expressed in peri-infarcted and infarcted regions of brain tissue, localizing in neuronal nuclei and cytoplasm, whilst being absent or very
\end{abstract}

weakly expressed in normal looking contralateral tissue. Exposure of human fetal brain neurons to oxygen-glucose deprivation also induced BTG2 expression in the cytoplasm and perinuclear regions of cells staining positive for propidium iodide (a marker of nuclear damage). Conclusions: BTG2 may be a modulator of cell survival and differentiation and could help to protect against cell death by inhibition of necrosis and/or apoptotic signalling pathways.

Copyright $\odot 2009$ S. Karger AG, Basel

\section{Introduction}

The extent of recovery from stroke is dependent on the survival of neurons, particularly in peri-infarcted regions, which are subject to the risk of permanent damage but are potentially salvageable. Neuronal survival is a complex process, requiring a fine balance between numerous protective and deleterious factors. The brain activates neuroprotective mechanisms in an attempt to counteract neurodestructive pathways. Recent studies have tried to identify novel markers which may impact upon neuronal survival after ischaemic stroke. Several

Prof. M. Slevin

ICCC

St. Pau Hospital

Barcelona (Spain)

Tel. +44 161247 1172, Fax +44161247 6325, E-Mail m.a.slevin@mmu.ac.uk 
Table 1. Patient data

\begin{tabular}{|c|c|c|c|c|c|c|c|c|c|c|c|}
\hline $\begin{array}{l}\text { Patient } \\
\text { No. }\end{array}$ & $\begin{array}{l}\text { Age/ } \\
\text { sex }\end{array}$ & $\begin{array}{l}\text { Survival after } \\
\text { stroke, days }\end{array}$ & $\begin{array}{l}\text { SSS on } \\
\text { admission }\end{array}$ & $\begin{array}{l}\text { SSS } \\
\text { final }\end{array}$ & $\begin{array}{l}\text { Hypercholes- } \\
\text { terolaemia }^{1}\end{array}$ & Obesity $^{2}$ & $\begin{array}{l}\text { Hyper- } \\
\text { tension }^{3}\end{array}$ & $\begin{array}{l}\text { Coronary } \\
\text { disease }\end{array}$ & $\begin{array}{l}\text { Atrial } \\
\text { fibrillation }\end{array}$ & $\begin{array}{l}\text { History } \\
\text { of TIA }\end{array}$ & Smoking \\
\hline 1 & $84 / \mathrm{M}$ & 3 & 18 & 0 & no & no & yes & yes & no & no & yes \\
\hline 2 & $85 / F$ & 5 & 8 & 0 & no & yes & yes & yes & no & no & no \\
\hline 3 & $51 / \mathrm{M}$ & 14 & 4 & 0 & no & no & yes & no & no & yes & no \\
\hline 4 & $86 / \mathrm{M}$ & 15 & 40 & 0 & yes & no & yes & yes & no & no & no \\
\hline 5 & $73 / \mathrm{M}$ & 26 & 35 & 0 & yes & yes & yes & yes & no & no & no \\
\hline 6 & $84 / F$ & 29 & 34 & 0 & yes & no & yes & yes & no & no & no \\
\hline 7 & $73 / \mathrm{M}$ & 29 & 29 & 18 & no & no & no & yes & yes & no & yes \\
\hline 8 & $60 / \mathrm{F}$ & 31 & 16 & 16 & yes & no & yes & yes & no & no & yes \\
\hline
\end{tabular}

SSS = Scandinavian stroke scale; TIA = transient ischaemic attack.

${ }^{1}$ Yes $=$ hypercholesterolaemia $>5.2 \mathrm{~mm} / \mathrm{l} .{ }^{2}$ Body mass index $>24 .{ }^{3}$ Diastolic $>90 \mathrm{~mm} \mathrm{Hg}$; systolic $>140 \mathrm{~mm} \mathrm{Hg}$.

members of fibroblast growth factor and hypoxia-inducible factor families, as well as leptin hormone and interleukin-6, are involved in neuroprotective brain mechanisms [for a review, see ref. 1]. There are currently no clinically proven neuroprotective drugs, and several drugs have failed in clinical trials because of toxicity [2] Glutamate (N-methyl-D-aspartate) and amino-methyl proprionic acid antagonists are in development, and one compound traxoprodil, an antagonist of the NR2B subtype of the N-methyl-D-aspartate receptor, appears promising. The identification of new molecules involved in neuroprotection might reduce patient cognitive impairment and mortality after stroke.

Using cDNA microarray, our previous studies have identified increased B-cell translocation gene 2 (BTG2) expression in peri-infarcted and infarcted regions of patients following acute ischaemic stroke [3]. BTG2 is a member of a newly identified family of anti-proliferative genes that has emerged as an important regulator of cell growth, differentiation and DNA damage repair by functioning as both an effecter of pRb and p53 action [4]. BTG2 was first described as an immediate early gene whose expression is induced in response to mitogenic as well as differentiating and anti-proliferative factors [5]. Although the biological functions of the BTG2 protein remain to be elucidated, several studies have attempted to identify the different cues capable of inducing its expression [6,7]. Of relevance to this work, nerve growth factor (NGF) and brain-derived neurotrophic factor, which are released after ischaemia, can activate a signalling pathway leading to $\mathrm{Bcl}-2$ activation and concomitantly inhibit p53, resulting in inhibition of neuronal apoptosis [8].
Since BTG2 may play a role as a protective factor in stroked brain tissue, here, we have examined its expression patterns in human brain in more detail.

\section{Materials and Methods}

\section{Human Brain Autopsy Specimens}

Human brain tissue samples were obtained from 9 patients who died from acute ischaemic stroke, with the approval of the local ethics committee. All patients were admitted with large middle cerebral artery strokes confirmed by CT scan or MRI (NIH Stroke Scale on admission $18 \pm 6$ ). The patients, 8 males and 1 female, were aged between 51 and 86 years and had survived between 3 and 37 days following ischaemic stroke (table 1). Full clinical examinations and routine blood parameters were determined on admission. Immediately after death, the body was put in a cold chamber and tissue was collected within $6 \mathrm{~h}$ of death. Tissue samples were taken from infarct and peri-infarcted zones, whilst controls were obtained from the contralateral hemisphere at the same time. The peri-infarcted areas were defined in tissue sections as the tissue immediately surrounding the infracted core which contained some necrotic cells and showed evidence of tissue disorganization and disruption of neuronal cell layers which was confirmed by histology. Sections were stained with 2,3,5-triphenyltetrazolium chloride which stains active mitochondria pink; therefore, non-stained areas represented stroke-affected cortical regions (data not included). Tissue specimens were immediately frozen in liquid nitrogen, kept at $-70^{\circ} \mathrm{C}$, and a portion of each sample was fixed in $10 \%$ formaldehyde and processed for histology, where subsequently haematoxylin and eosin was used to determine tissue morphology [9].

\section{Human Cerebral Cortical Neurons}

Primary cultures enriched in cerebral cortical neurons were established from fetal brain tissue, following the procedure described previously [3]. Brain tissue was obtained from fetal specimens of 14-19 weeks gestational age, legally aborted and after 
written informed consent from donors. Permission for use of human tissue was obtained from the ethics committee of the Consejo Superior de Investigaciones Científicas. Briefly, tissues were diced into small cubes and dissociated by incubation at $37^{\circ} \mathrm{C}$ with $0.025 \%$ trypsin and $40 \mu \mathrm{g} / \mathrm{ml}$ DNase in PBS for $10 \mathrm{~min}$. Dissociated cells were resuspended in miminum essential medium supplemented with $5 \%$ horse serum, $2 \mathrm{mM}$ glutamine, $25 \mathrm{mM}$ D-glucose, $0.25 \mu \mathrm{g} / \mathrm{ml}$ fungizone, $50 \mu \mathrm{g} / \mathrm{ml}$ gentamycin and $1 \%$ nonessential amino acids. To obtain neuron-enriched cultures, cells were seeded at a density of $3 \times 10^{5}$ cells $/ \mathrm{cm}^{2}$ in multiwall plates previously coated with $10 \mu \mathrm{g} / \mathrm{ml}$ poly-L-lysine, maintained in a humidified $\mathrm{CO}_{2}$ incubator and fed weekly. Experimental procedures were performed after 12-14 days in vitro. Selected experiments were done after 2 days in vitro. The neuronal cultures consisted of $70-85 \%$ neurons, $15-30 \%$ astrocytes, $1-2 \%$ microglia and $0.1-1 \%$ oligodendroglia.

\section{In vitro Oxygen-Glucose Deprivation}

For oxygen-glucose deprivation (OGD) experiments, the above culture medium was replaced by glucose-free medium containing $2 \%$ fetal bovine serum (TCS CellWorks, Buckingham, UK), and cells were cultured at $37^{\circ} \mathrm{C}$ in a humidified chamber with $95 \% \mathrm{~N}_{2}, 1 \% \mathrm{O}_{2}$ and $5 \% \mathrm{CO}_{2}$ for $14 \mathrm{~h}$ followed by $24 \mathrm{~h}$ reperfusion in fresh medium containing $4.5 \mathrm{~g} / \mathrm{l}$ glucose. This resulted in approximately $30 \%$ of cells undergoing apoptosis after OGD and $60 \%$ following re-oxygenation, as determined from our pilot studies. Cells cultured in normoxic conditions without glucose deprivation were used as controls. The fluorescent exclusion dye propidium iodide is widely used as a vital dye in tissue culture systems and labels the nuclear DNA and, in particular, changes in DNA structure caused by strand breaks in dying and apoptotic cells which lack an intact plasma membrane. In some experiments, propidium iodide $(10 \mu \mathrm{g} / \mathrm{ml})$ was added to the cultures $1 \mathrm{~h}$ before the end of the experiment to stain dead and dying cells, as described in our previous studies [10].

\section{Protein Extraction and Western Blotting}

Proteins were extracted from tissues, and the protein concentration of each sample was determined using the BioRad assay. For Western blotting, $10 \mu \mathrm{g}$ of protein lysate in RIPA buffer was separated by sodium dodecyl sulphate polyacrylamide gel electrophoresis $(13 \% \mathrm{w} / \mathrm{v})$, and the proteins were electroblotted onto nitrocellulose filters as described previously [10]. Filters were blocked in $1 \% \mathrm{w} / \mathrm{v}$ bovine serum albumin in Tris-buffered saline Tween and stained overnight at $4^{\circ} \mathrm{C}$ with antibodies to BTG2 (sc30342; Santa Cruz Biotechnology, Inc., Santa Cruz, Calif., USA) diluted in 1\% bovine serum albumin: goat anti-BTG2 (1:100) and $\alpha$-actin (1:1,000; Sigma, Dorset, UK) in 5\% w/v milk in Tris-buffered saline Tween for $1 \mathrm{~h}$. Blots were developed with the ECL detection system (Amersham, UK). The relative intensities of the bands were measured in an LKB densitometer (Victoria, Australia). Results are semi-quantitative and are given as a numerical (fold) change compared with the control (contralateral tissue) which was given an arbitrary value of 1.0. All experiments were performed twice and a representative example is shown.

\section{Immunohistochemistry}

Paraffin-embedded tissue samples were processed and serial 5 - $\mu \mathrm{m}$ sections were cut. The avidin-biotin peroxidase (ABC Vectastin kit; Vector Laboratories, Peterborough, UK) method was used, and goat anti-BTG2 antibody was used at a dilution of 1:50. Paraffin-embedded sections were deparaffinized, rehydrated and boiled for $10 \mathrm{~min}$ in an antigen unmasking solution of concentrated citric acid, $\mathrm{pH}$ 6.0. Slides were incubated in $0.5 \% \mathrm{v} / \mathrm{v} \mathrm{H}_{2} \mathrm{O}_{2}$ in methanol for $30 \mathrm{~min}$, with normal 5\% v/v rabbit serum for 20 min and then with a primary antibody (1:50 diluted in $1 \% \mathrm{v} / \mathrm{v}$ rabbit serum) for $1 \mathrm{~h}$, followed by $1 \mathrm{~h}$ incubation with biotinylated secondary antibody made in rabbit serum (diluted 1:200 in 1\% $\mathrm{v} / \mathrm{v}$ rabbit serum) and finally with $\mathrm{ABC}$ complex (diluted 1:50) for $30 \mathrm{~min}$ at room temperature. Staining was completed after incubation with diaminobenzidine substrate chromogen solution for 3-10 min. Slides were counterstained with haematoxylin, dehydrated, cleared and mounted in DPX. Negative control slides were performed in parallel, where the primary antibody was replaced with PBS, and sections were subsequently processed as above (data not included).

\section{Immunofluorescence}

Cultured cells were fixed in $4 \%$ paraformaldehyde for 20 min, permeabilized with $0.2 \%$ Triton X-100 for 10 min, blocked with normal serum and stained with the primary antibody as above, followed by $1 \mathrm{~h}$ incubation with FITC-conjugated secondary antibodies (1:200) at room temperature. Negative control cells were performed in parallel, where the primary antibody was replaced with PBS and sections processed as above (data not included).

\section{Results}

\section{Western Blotting Showed Increased Expression of BTG2 in Stroke-Affected Tissue of Seven out of Eight Patients Examined}

A comparison between contralateral and peri-infarcted tissue showed that 5 out of 8 patients had increases of at least 1.5 fold in damaged tissue (range 1.5-2.0; fig. 1). Similarly, in infarcted tissue, 6 out of 8 patients had increased BTG2 expression (range 1.5-4.0).

\section{BTG2 Protein Expression Was Increased in Neurons in Peri-Infarcted and Infarcted Regions of Human Stroke Tissue}

Immunohistochemistry demonstrated a strong staining of BTG2 in peri-infarcted (fig. 2a, b) and infarcted (fig. 2c, d) areas with specific localization to neuronal cytoplasm and nuclei (arrows). Occasionally, we found BTG2 staining in microvessels (fig. 2b; arrows), but the majority of vessels were negative. Figures $2 \mathrm{f}$ and $2 \mathrm{~g}$ show examples of neuronal nuclei in peri-infarcted and infarcted regions, respectively, which stained strongly for BTG2. Only very weak staining was seen in normal looking neurons from the contralateral hemisphere (fig. 2e; arrows point to negatively stained neurons). 
a

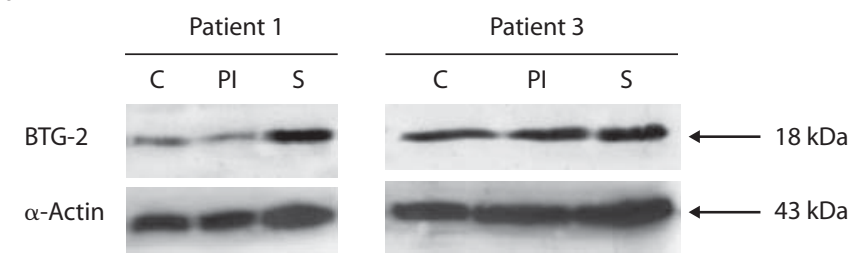

b

\begin{tabular}{|c|c|c|c|}
\cline { 2 - 4 } \multicolumn{1}{c|}{} & Contralateral & Peri-infarcted area & Stroke area \\
\hline Patient 1 & 1 & 1.5 & 4.6 \\
\hline Patient 2 & 1 & 2.0 & 1.5 \\
\hline Patient 3 & 1 & 2 & 1.5 \\
\hline Patient 4 & 1 & 1.5 & 0.5 \\
\hline Patient 5 & 1 & 1 & 4 \\
\hline Patient 6 & 1 & 2 & 2.5 \\
\hline Patient 7 & 1 & 0.5 & 1.5 \\
\hline Patient 8 & 1 & 1 & 0.5 \\
\hline
\end{tabular}

Fig. 1. Western blot analysis of BTG2 in contralateral hemisphere, peri-infarcted and infarcted regions of patients following acute ischaemic stroke. a Control areas from stroke patients had lower expression of BTG2 than peri-infarcted and stroke areas; representative Western blots for patients 1 and 3 are shown. $\mathrm{C}=\mathrm{Con}-$ tralateral area; PI = peri-infarcted area; $\mathrm{S}=$ stroke or infarcted area. $\alpha$-Actin was used as a control to demonstrate equality of protein loading. $\mathbf{b}$ Table showing fold differences in BTG2 expression obtained by scanning densitometry.

Immunofluorescence Showed Increased Protein

Expression of BTG2 in Neurons following OGD

Immunofluorescence demonstrated an increase in staining of BTG2 in human fetal brain neurons following $8 \mathrm{~h}$ of OGD (fig. 3). BTG2 upregulation was most pronounced in the cytoplasm of propidium iodide-positive neurons, suggesting an association with cell apoptosis.

\section{Discussion}

BTG2 is a member of a novel anti-proliferative gene family and plays a role in transcription regulation. BTG genes are considered immediate early genes whose expression is induced in response to mitogenic as well as differentiating and anti-proliferative factors [11]. In this study, we have seen a strong upregulation of BTG2 protein expression in stroke-affected regions. In these areas, we found both cytoplasmic and nuclear BTG2-positive staining in neurons. In contrast, only weak or no staining was seen in normal looking neurons from the contralateral hemisphere. In vitro studies showed increased expression of BTG2 in neurons following OGD. This suggests that upregulation of BTG2 expression in neurons is induced following ischaemic events.

There are few previous publications referring to the involvement of BTG2 in ischaemic diseases or stroke. BTG2 was induced following brief spinal ischaemia using a rat balloon occlusion model [12], and increased expression of BTG2 mRNA was also observed in the kidney after 30-min ischaemia [13]. Previous studies have shown that oxidative DNA damage precedes DNA fragmentation in neurons after experimental stroke [14], and that these events are followed by the triggering of different cellular processes including apoptosis [15].

In this respect, it is interesting to note that several previous studies have demonstrated an anti-apoptotic role for BTG2 in neuronal cell cultures. For example, BTG2 protected terminally differentiated $\mathrm{PC} 12$ cultures against apoptosis elicited by NGF deprivation [16], and also prevented apoptosis of a terminally differentiated rat pheochromocytoma cell line (PC12) [17]. In response to DNA damage, eukaryotic cells can delay cell cycle progression at both G1 into S, and G2 into M phases by induction of anti-proliferative genes, such as BTG2, which may be one mechanism through which it helps to protect against neuronal cell death.

Our results suggest that BTG2 upregulation in the brain following ischaemic stroke might form part of a protective mechanism against apoptosis. BTG2 expression is normally induced through a p53-dependent mechanism, and its function may be relevant to cell cycle control, through regulation of the G1/S transition of the cell cycle, and to cellular response to DNA damage [5]. The study by Rouault et al. [5] showed that differentiated embryonic stem cells from which BTG2 has been ablated underwent apoptosis following DNA damage because of a failure in growth arrest. Similarly, el-Ghissassi et al. [17] showed that inhibition of BTG2 mRNA with specific antisense oligonucleotide promoted programmed cell death in NGF differentiated cells. This suggests that BTG2 triggers a physiological role in the control of cell cycle arrest following DNA damage and other types of cellular stress.

BTG2 appears to trigger inhibition of the cell cycle through arrest of cells in the G1 phase via inhibition of cyclin D1 transcription and, in this way, contributes to neuron differentiation [18]. Cell cycle arrest is known to be an essential preliminary requirement for terminal dif- 

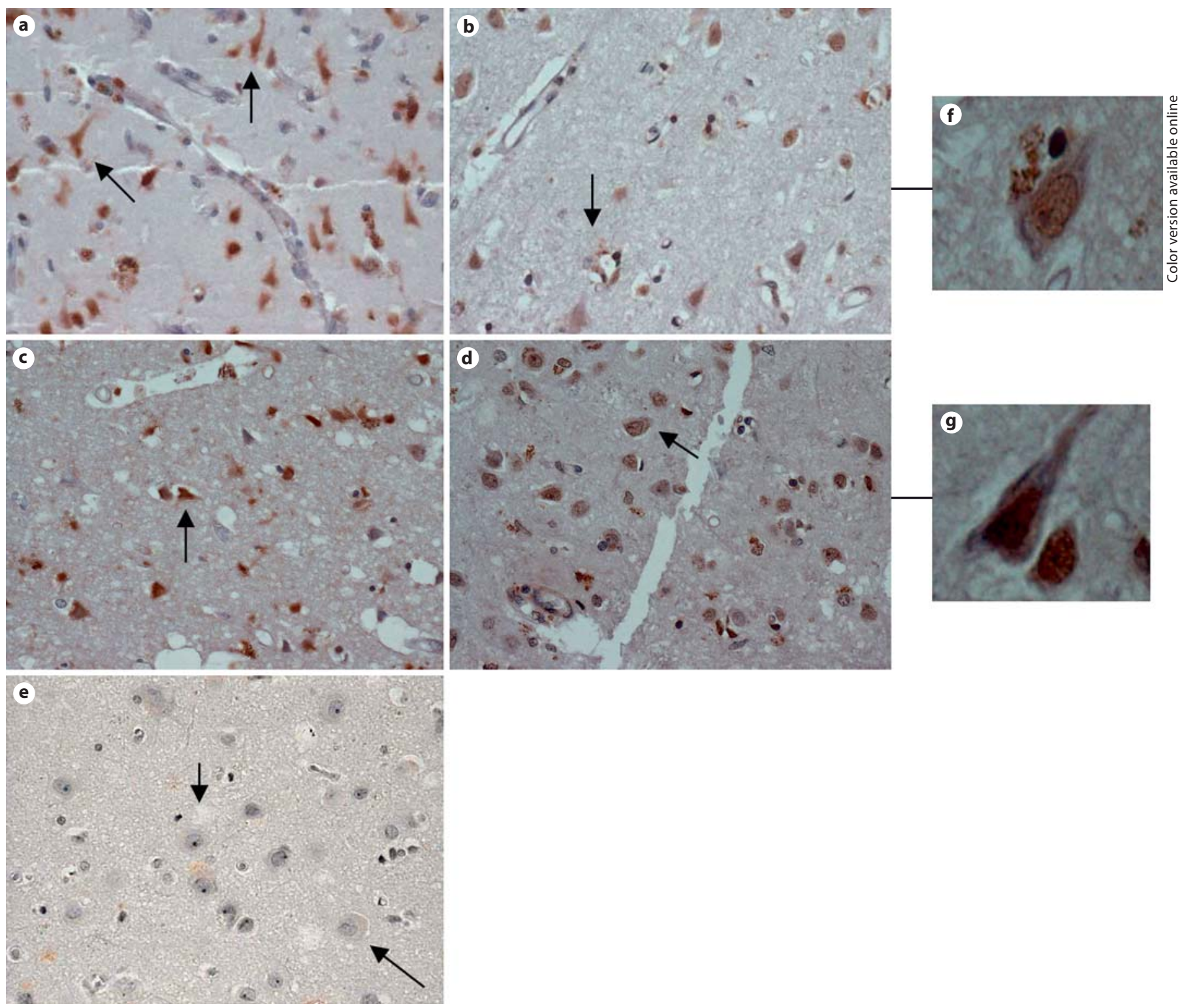

Fig. 2. Immunohistochemistry of BTG2. a Strong expression of BTG2 in neurons from the peri-infarcted region. b Occasional staining of microvessels (patient 4 ). a, b $\times 100$. c, $\mathbf{d}$ Infarcted region with more intense nuclear staining (patient 1 ; arrows). $\times 100$

e Portion from the contralateral hemisphere of patient 3 and weak BTG2 staining of neurons (arrows). $\times 100 . \mathbf{f}, \mathbf{g}$ Magnified images showing nuclear staining of a neuron of patient $4(\mathbf{f})$ and patient 1 (g). $\times 200$.

ferentiation and, in this context, previous studies have highlighted a potential role for BTG2 in the control of neurogenesis through induction of Math1 which is a transcription factor required for neuronal differentiation [19].

BTG2 was originally isolated as a gene induced by NGF during neuronal differentiation of rat PC12 cells, and it is a marker of neuronal birth in vivo. The localiza- tion of BTG2 mRNA in the adult central nervous system in specialized structures, such as the ventricular zone, suggests it could be important in maintaining the brain stem cell population [20], and therefore, directly influence this process under pathological conditions, such as in brain ischaemia accompanying a stroke [21-24]. Our in vivo studies showed that BTG2 was present in both the cytoplasm and the nucleus of stroke-affected neurons, 

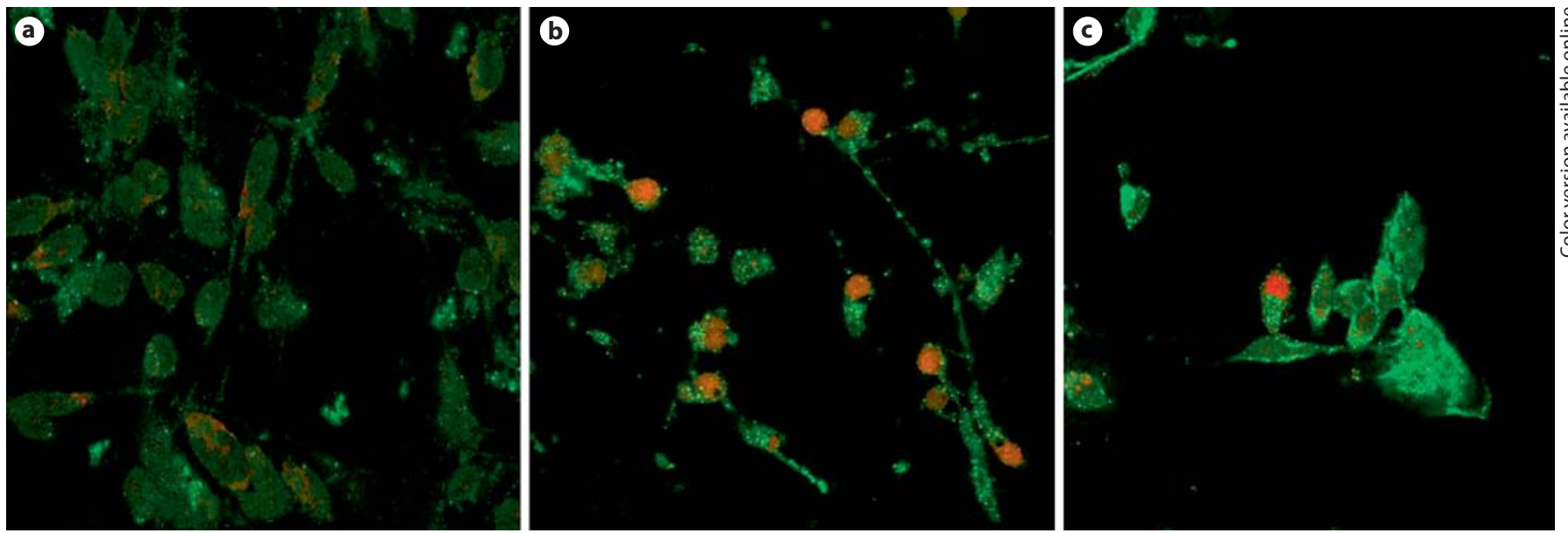

Fig. 3. Human fetal brain neurons showed increased protein expression of BTG2 following OGD. a Untreated neurons showed almost no BGT2 expression (control). b Neurons exposed to OGD showed upregulation of BTG2 protein (BTG2, FITC, green; prop-

idium iodide, red, showing cell apoptosis). c Magnified portion of the image showing cytoplasmic expression. $\times 100$. The colours refer to the online version of the figure.

whilst in vitro following OGD, the expression was also increased but limited to the cytoplasm. BTG2 is able to behave as a transcriptional coregulator in different model systems, although the molecular mechanisms of this action are probably multiple and often unclear. Previous studies showed that following treatment with the cell-differentiating agent retinoic acid, BTG2 detached from its transcriptional nuclear receptor RAR $\alpha$ and translocated from the nucleus to the cytoplasm. These events prime histone $\mathrm{H} 4$ demethylation and acetylation, increase cell differentiation and could be events similar to those which occur following OGD and hypoxia in vitro in our human fetal neurons [25]. The presence of the immediate early gene BTG2 simultaneously in neuronal nuclei after stroke may be an indication of the complexity and greater sever- ity of signalling processes in the local microenvironment including expression of growth factors such as NGF, and be associated with its function as a p53 transcriptional target following DNA damage [26].

In conclusion, the role of BTG2 in neuronal survival following ischaemic stroke should be examined in greater detail to identify its importance in mediating signalling pathways associated with stroke repair.

\section{Acknowledgements}

We would like to thank the Fundacion BBVA for the generous support of Prof. Mark Slevin through the award of the BBVA Chair in Clinical Biomedicine at the ICCC, St Pau Hospital, Barcelona, Spain.

\section{References}

Slevin M, Krupinski J, Kumar P, Gaffney J, Kumar S: Gene activation and protein expression following ischaemic stroke: strategies towards neuroprotection. J Cell $\mathrm{Mol}$ Med 2005;9:85-102.

2 Ginsberg MD: Neuroprotection for ischemic stroke: past, present and future. Neuropharmacology 2008;55:363-389.

-3 Slevin M, Gaffney J, Kumar S: Angiogenic oligosaccharides of hyaluronan induce multiple signalling pathways impacting vascular endothelial cell mitogenesis and wound healing. J Biol Chem 2002;277:4104641059 .
Matsuda S, Rouault J, Magaud J, Berthet C: In search of a function for the TIS21/PC3/ BTG1/TOB family. FEBS Lett 2001;497:6772 .

5 Rouault JP, Falette N, Guéhenneux F, Guillot C, Rimokh R, Wang Q, Berthet C, MoyretLalle C, Savatier P, Pain B, Shaw P, Berger R, Samarut J, Magaud JP, Ozturk M, Samarut C, Puisieux A: Identification of BTG2, an antiproliferative p53-dependent component of the DNA damage cellular response pathway. Nat Genet 1996;14:482-486. 
6 Bradbury A, Possenti R, Shooter EM, Tirone F: Molecular cloning of PC3, a putatively secreted protein whose mRNA is induced by nerve growth factor and depolarization. Proc Natl Acad Sci USA 1991;88:3353-3357.

$\checkmark 7$ Fletcher BS, Lim RW, Varnum BC, Kujubu DA, Koski RA, Herschman HR: Structure and expression of TIS21, a primary response gene induced by growth factors and tumor promoters. J Biol Chem 1991;266:1451114518.

8 Chan SL, Yu VC: Proteins of the bcl-2 family in apoptosis signalling: from mechanistic insights to therapeutic opportunities. Clin Exp Pharmacol Physiol 2004;31:119-128.

$\checkmark 9$ Eke A, Conger KA, Anderson M, Garcia JH: Histological assessment of neurons in rat models of cerebral ischemia. Stroke 1990;21: 299-304.

-10 Slevin M, Krupinsky J, Mitsios N, Perikleous C, Cuadrado E, Montaner J, Sanfeliu C, Luque A, Kumar S, Kumar P, Gaffney J: Leukaemia inhibitory factor is over-expressed by ischaemic brain tissue concomitant with reduced plasma expression following acute stroke. Eur J Neurol 2008;15:29-37.

-11 Tirone F: The gene PC3 (TIS21/BTG2), prototype member of the PC3/BTG/TOB family: regulator in control of cell growth, differentiation, and DNA repair? J Cell Physiol 2001;187:155-165.

12 Carmel JB, Kakinohana O, Mestril R, Young W, Marsala M, Hart RP: Mediators of ischemic preconditioning identified by microarray analysis of rat spinal cord. Exp Neurol 2004; 185:81-96.
13 Fiedler F, Mallo GV, Bödeker H, Keim V, Dagorn JC, Iovanna JL: Overexpression of the PC3/TIS21/BTG2 mRNA is part of the stress response induced by acute pancreatitis in rats. Biochem Biophys Res Commun 1998; 249:562-565.

14 Cui J, Holmes EH, Greene TG, Liu PK: Oxidative DNA damage precedes DNA fragmentation after experimental stroke in rat brain. FASEB J 2000;14:955-967.

15 Clarke AR, Purdie CA, Harrison DJ, Morris RG, Bird CC, Hooper ML, Wyllie AH: Thymocyte apoptosis induced by p53-dependent and independent pathways. Nature 1993; 362:849-852.

16 Corrente G, Guardavaccaro D, Tirone F: PC3 potentiates NGF-induced differentiation and protects neurons from apoptosis. Neuroreport 2002;13:417-422.

17 el-Ghissassi F, Valsesia-Wittmann S, Falette N, Duriez C, Walden PD, Puisieux A: BTG2(TIS21/PC3) induces neuronal differentiation and prevents apoptosis of terminally differentiated PC12 cells. Oncogene 2002;21:6772-6778.

18 Guardavaccaro D, Corrente G, Covone F Micheli L, D’Agnano I, Starace G, Caruso M, Tirone F: Arrest of G(1)-S progression by the p53-inducible gene PC3 is Rb dependent and relies on the inhibition of cyclin D1 transcription. Mol Cell Biol 2000;20:1797-1815.
19 Canzoniere D, Farioli-Vecchioli S, Conti F, Ciotti MT, Tata AM, Augusti-Tocco G, Mattei E, Lakshmana MK, Krizhanovsky V, Reeves SA, Giovannoni R, Castano F, Servadio A, Ben-Arie N, Tirone F: Dual control of neurogenesis by PC3 through cell cycle inhibition and induction of Math1. J Neurosci 2004;24:3355-3369.

$>20$ Terra R, Luo H, Qiao X, Wu J: Tissue-specific expression of $\mathrm{B}$-cell translocation gene 2 (BTG2) and its function in T-cell immune responses in a transgenic mouse model. Int Immunol 2008;20:317-326.

21 Liu J, Solway K, Messing RO, Sharp FR: Increased neurogenesis in the dentate gyrus after transient global ischemia in gerbils. J Neurosci 1998;18:7768-7778.

22 Arvidsson A, Collin T, Kirik D, Kokaia Z, Lindvall O: Neuronal replacement from endogenous precursors in the adult brain after stroke. Nat Med 2002;8:963-970.

23 Palmer TD, Willhoite AR, Gage FH: Vascular niche for adult hippocampal neurogenesis. J Comp Neurol 2000;425:479-494.

24 Panchision DM, McKay RD: The control of neural stem cells by morphogenic signals. Curr Opin Genet Dev 2002;12:478-487.

25 Passeri D, Marcucci A, Rizzo G, Billi M, Panigada M, Leonardi L, Tirone F, Grignani F: BTG2 enhances retinoic acid-induced differentiation by modulating histone $\mathrm{H} 4$ methylation and acetylation. Mol Cell Biol 2006; 1:5023-5032.

26 Duriez C, Moyret-Lalle C, Falette N, ElGhissassi, Puisieux A: BTG2, its family and its tutor. Bull Cancer 2004;91:242-253. 